\title{
ACOMPAÑAMIENTO DEL TRÁFICO DE MARACUYÁ POR UN PUESTO DE INSPECCIÓN AGROPECUARIO
}

\author{
José Carlos Roseno de LIMA'; Nadja Helaine de ARAÚJO²; Gil Dutra FURTADO³
}

\begin{abstract}
${ }^{1}$ Licenciado em Ciências Agrárias/Universidade Federal da Paraíba (UFPB); Técnico em Agropecuária/UFPB; Técnico da Defesa Agropecuária/Secretaria de Estado do Desenvolvimento da Agropecuária e da Pesca (SEDAP/PB), Brasil. E-mail: jcarlosroseno@gmail.com

${ }^{2}$ Licenciada em Ciências Biológicas/UFPB; Mestra em Desenvolvimento e Meio Ambiente (PRODEMA)/UFPB, Brasil. E-mail: nadjahelainejp@hotmail.com

${ }^{3}$ Engenheiro Agrônomo/UFPB; Doutor em Psicobiologia/Universidade Federal do Rio Grande do Norte (UFRN); Agrônomo-Sócio da Cooperativa de Agronegócio (COOPAGRO), Brasil. E-mail: gdfurtado@hotmail.com
\end{abstract}

Resumen. El tránsito de los productos agrícolas presenta un grado de vulnerabilidad representando un riesgo inminente para las plantaciones, siendo uno de los grandes problemas para la agricultura que es vulnerable a varias especies invasoras exóticas (EIE), pudiendo incurrir en el aumento de los gastos de cultivo y caída en la generación de frutos, además de comprometer y provocar impactos negativos al medio ambiente causados por las medidas de controles químicos que pueden utilizarse. De esta forma, el objetivo del presente trabajo es estudiar el tráfico comercial de maracuyá que fluye por la barrera fitosanitaria de Tacima, estado de la Paraíba en brasil; y mencionar las plagas y enfermedades fitosanitarias que estas pueden ocasionar. Por medio de una investigación bibliográfica, revisiones documentales, entre otros; fue constatado una disminución en el número de frutos de maracuyá en toneladas entre los años 2012 y 2015. Las barreras fitosanitarias contribuyeron para la educación de los agricultores y la disminución de la posibilidad de transporte de plagas y enfermedades en el local de estudio.

Palabras clave: Barreras fitosanitarias; Tránsito de vegetales; Nordeste brasileño.

\section{MONITORING THE TRAFFIC OF PASSION FRUIT BY AN AGRICULTURAL INSPECTION OFFICE}

Abstract. The transit of agricultural products presents a degree of vulnerability representing an imminent risk to the crops, being one of the greatest problems for the agriculture that is vulnerable to several species of exotic invaders (EIE), being able to incur in the expenses of culture and fall in the generation of the fruits, in addition to compromising and causing damage to the environment, due to the chemical control measures that can be used. In this way, the objective of this search is to study the commercial traffic of passion fruit that passes through the phytosanitary barrier of Tacima, state of 
Paraíba, and mention the pests and phytosanitary diseases that can occur. Through a bibliographical research, documentary reviews, among others, it was observed a decrease in the number of passion fruit in tons throughout the years of 2012 to 2015. The phytosanitary barriers contributed to the education of the farmers and the reduction of the possibility of transportation of pests and diseases at the place of study.

Keywords: Fitosanitary barriers; Transit of vegetables; Brazilian Northeast.

\section{ACOMPANHAMENTO DO TRÁFEGO DE MARACUJÁ POR UM POSTO DE FISCALIZAÇÃO AGROPECUÁRIO}

Resumo. O trânsito dos produtos agrícolas apresenta um grau de vulnerabilidade, representando um risco iminente para as lavouras, sendo um dos grandes problemas para a agricultura que é vulnerável a várias espécies invasoras exóticas (EIE), podendo ocorrer um aumento nas despesas de cultivo e queda na geração dos frutos, além de comprometer e provocar prejuízos ao meio ambiente, por conta das medidas de controles químicos que se podem utilizar. Desta forma, o objetivo do presente trabalho é estudar o tráfego comercial de maracujá que passa pela barreira fitossanitária de Tacima, estado da Paraíba, e mencionar as pragas e doenças fitossanitárias que estas podem decorrer. Por meio de uma pesquisa bibliográfica, revisões documentais, dentre outros, foi constatado uma queda no número dos frutos de maracujá em toneladas ao longo dos anos de 2012 a 2015. As barreiras fitossanitárias contribuíram para a educação dos agricultores e a diminuição da possibilidade de transporte de pragas e doenças no local de estudo.

Palavras-chave: Barreiras fitossanitárias, Trânsito de vegetais; Nordeste brasileiro.

\section{INTRODUCCIÓN}

En Brasil se observa que las riquezas de los productos agrícolas están directamente ligadas a los recursos naturales que acaban proporcionando una producción expresiva (BUAINAIN; VIEIRA; CURY, 2011). Así, la dinámica que la agricultura nacional brasilera proporciona es intensa y posee gran capacidad de transformar la vida de la población que vive de la agricultura.

Esta abundancia agrícola que genera riquezas y estabilidad social, también puede generar trastornos si no es bien acompañada por técnicos y responsables calificados, principalmente en lo concerniente al transporte y comercialización cuando pasan de una región para otra (OLIVEIRA; NEVILLE; VALOIS, 2001; CACHATORI, 2011), ya que pueden contribuir con la dispersión de organismos invasores patogénicos. 
Lima (2018) menciona que la introducción de especies invasoras exóticas puede acarrear trastornos en los dividendos y caída en las plantaciones agrícolas, además de comprometer el equilibrio del medio ambiente (DIAS; OLIVEIRA; PAIVA, 2002; VIEIRA, 2002).

El servicio de las barreras fitosanitarias se muestra imprescindible en este sentido, pues provee mayor seguridad para los agricultores, proporcionando mejor inserción de productos de calidad en el mercado consumidor (ADAPEC, 2017). Estas barreras colaboran con la preservación patrimonial fitosanitaria al orientar el sector productivo sobre las normas vigentes, además de la propia inspección de los productos (FERNANDES, 2016). Este se muestra viable porque las barreras fitosanitarias localizadas en las fronteras de los estados, realizan evaluaciones de las cargas, identificaciones y evaluaciones del estado fitosanitario de los vegetales transportados (AGRODEFESA, 2014), garantizando procedimientos transparentes y confiables de prevención de la sanidad vegetal (PARANÁ, 1995; AGED, 2017).

La maracuyá se ha destacado entre las frutas producidas en Brasil (ARAÚJO; ARAÚJO; CORREIA et al., 2005), siendo que en 2011 el país tenía una producción de 703.489 toneladas. El Estado de Paraíba es un productor de maracuyá que en 2011 tuvo una producción de 5.974 toneladas, además de otros productos vegetales, lo que demuestra la importancia que debemos dar para las barreras fitosanitarias como una barrera para prevenir la transmisión de plagas y enfermedades de este Estado (EMBRAPA, 2016).

A modo de ejemplo de lo que ocurre con otras culturas en la región, se observa que son necesarios cursos de capacitación que contribuyan a los productores para mejorar las prácticas adoptadas y garantizar la sostenibilidad de la cultura para la región productora (LIMA et al., 2009).

Barreras fitosanitarias deben quedar estratégicamente localizadas, pues son responsables por la inspección del traslado de los vegetales, bien como de productos y subproductos de origen vegetal, que buscan impedir la entrada de plagas y enfermedades por los límites entre estados y municipios, garantizando la sanidad vegetal (HILMAN, 2013; AGED, 2017).

Las inspecciones son realizadas a través de estructuras fijas o móviles que buscan evitar el riesgo de diseminación de las especies invasoras, principalmente las reglamentadas, inspeccionando el tránsito de vegetales y sus partes (frutas, granos, materiales de propagación, entre otros) (HILMAN, 2013). En todas las regiones del país existen 
restricciones de transporte de cargas vegetales, por poseer plagas cuarentenarias (BRASIL, 2008). Por eso los profesionales responsables por las barreras, obedecen a las determinaciones establecidas para el tránsito de vegetales, a través de Instrucción Normativa Específica del MAPA (Ministério da Agricultura, Pecuária e Abastecimento), siguiendo la legislación estadual complementaria. Estas barreras también contribuyen en el rastreo de los productos, pues fiscalizan las cargas y los documentos implicados en el mencionado sistema, especialmente el PTV, Permiso de Tránsito Vegetal (BRASIL, 2007).

Este artículo trabajó con los datos oriundos de la barrera fitosanitaria del Puesto de Inspección Agropecuario de la Ciudad de Tacima (Paraíba, Brasil), en el acompañamiento del tráfico de las frutas de maracuyá (Passiflora edulis), durante los años de 2012 a 2015, haciendo alusión a la importancia del puesto de inspección agropecuario y calificar el tráfico de maracuyá e identificar las plagas que este tráfico puede transmitir.

\section{MATERIALES Y MÉTODOS}

La presente investigación comprendió un periodo de 2012 a 2015, colectando informaciones en el puesto agropecuario de la ciudad de Tacima, que está localizada en la BR 073, seguimiento posterior de la ciudad, en latitud -6.472965 y longitud -35.633497, próxima a los límites entre los estados de Paraíba y Río Grande del Norte, local en que se realiza la inspección de entrada y salida de animales, vegetales además de sus subproductos. Se utilizó un enfoque cualitativo y cuantitativo, revisión de literatura, búsqueda documental, evaluaciones de campo y evaluaciones de datos históricos de monitoreo y control del tránsito vegetal, con los datos transformados en porcentajes para mejor descripción de los datos obtenidos (GIL, 2002).

\section{RESULTADOS}

El tránsito de maracuyá en la región de Tacima varió durante los años de 2012 hasta el año de 2015, donde el mayor volumen transportado fue en 2012, con 30,9 toneladas y el menor fue registrado en 2013, con apenas 4 toneladas (Fig. 1). En el gráfico puede observarse cinco momentos que el valor es " 0 ", sin embargo fueron momentos donde ocurrieron fallas en la colecta de datos y deben ser desconsideradas para este estudio, pues en todos los meses ocurrió tráfico de maracuyá. 


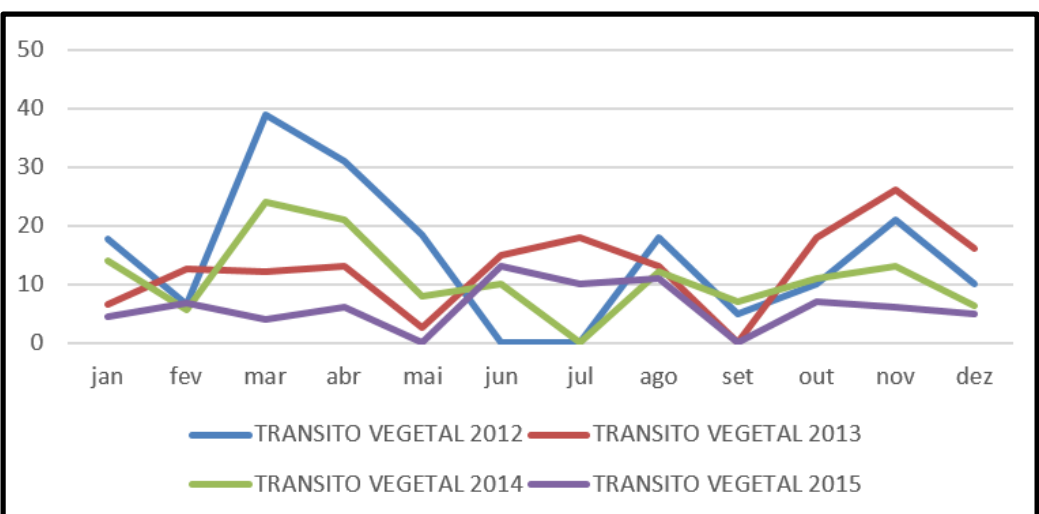

Figura 1.Variación del tráfico de maracuyá, entre 2012 y 2015 en la región de Tacima.

En el gráfico puede observarse que ocurre una disminución del flujo de maracuyá en esta barrera, y que los picos de mayor circulación de frutas ocurren en momentos distintos durante los cuatro años observados. En 2012 y 2014 el pico es notado en marzo, en el año 2013 ocurre en noviembre y en 2015 ocurre en junio. Estas variaciones están ligadas a varios motivos, como oferta de mercado y la propia irregularidad de las lluvias, ya que muchos pequeños agricultores no tienen como implementar sistemas de irrigación para conducir el cultivo.

La observación del gráfico demuestra una fuerte irregularidad entre los años estudiados. Esta irregularidad demuestra que la cultura queda expuesta a influencia de centros de consumidor, agriculturas similares regionales, alteraciones ambientales, aciertos comerciales; a ejemplo de otros varios motivos que contribuirán para debilitar y exponer el tráfico de frutas de maracuyá a una alta posibilidad de trasmisión de plagas y enfermedades comunes a esta cultura, entre el punto de origen de la producción y el punto de comercialización, que pasan por la barrera de Tacima.

El total en toneladas de maracuyá que pasó por la barrera de Tacima, se destaca que el pico máximo de 176,6 toneladas fue registrado en el año de 2012, en cuanto que el menor valor fue de 73,3 toneladas registrado en el año de 2015 (Fig. 2). 


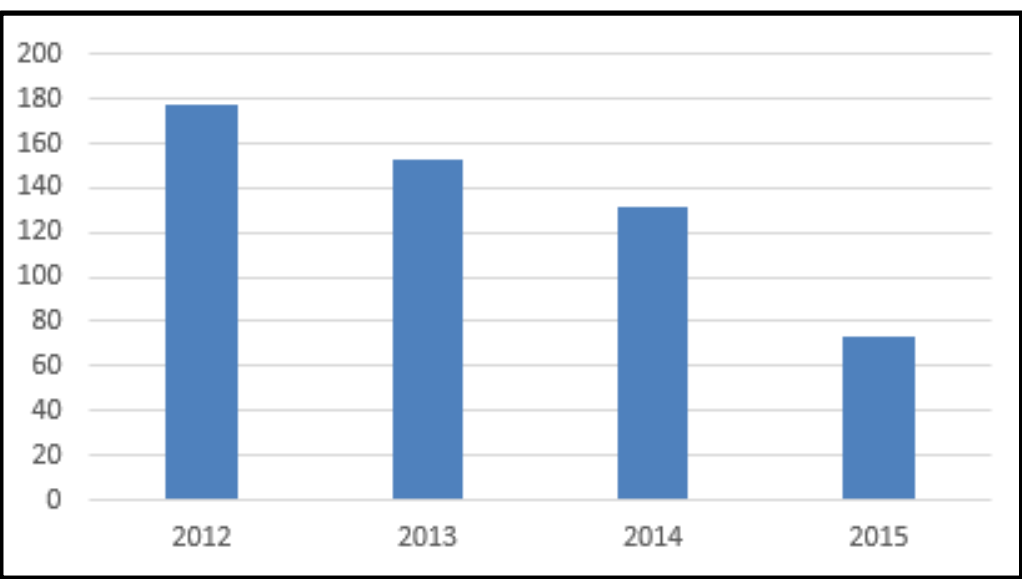

Figura 2. Tránsito total anual de maracuyá (en toneladas) en la barrera fitosanitaria de Tacima, Paraíba, Brasil.

La evolución de los datos con el pasar de los años observados demuestra que esta cultura viene presentando una acentuada disminución de tránsito por eta barrera fitosanitaria, lo que puede indicar que varios puntos flotantes (de difícil control) podrán estar llevando las frutas para otro mercado consumidor, contribuyendo a la disminución de este elemento en esta barrera. Sin embargo, independiente de este, el peligro de transmisión de plagas y enfermedades todavía es real, y por eso esta barrera continua desarrollando un importante papel de prevención para la región y el estado.

Los datos aquí encontrados están de acuerdo con los datos presentados a nivel de Brasil y su región nordeste, que indican caídas en los niveles de producción de esta cultura en el paso de esta linea de tiempo estudiada, sin embargo cuando se observa la producción que ocurrió en el estado de Paraíba, se observa lo contrario (Tab. 1).

Tabla 1. Cuadro de evolución de la producción de maracuyá en Brasil, en el Nordeste brasileño y en Estado del Paraíba.

\begin{tabular}{lllll}
\hline Local & Año & $\begin{array}{l}\text { Área recolectada } \\
\text { (ha) }\end{array}$ & $\begin{array}{l}\text { Producción } \\
(\mathbf{t})\end{array}$ & $\begin{array}{l}\text { Rendimiento } \\
\text { (t/ha) }\end{array}$ \\
\hline Brasil & 2012 & 61.631 & 923.035 & 14.98 \\
\cline { 2 - 5 } & 2015 & 49.889 & 703.489 & 14.14 \\
\hline $\begin{array}{l}\text { Nordeste } \\
\text { brasileño }\end{array}$ & 2012 & 46.153 & 671.421 & 14.55 \\
\hline $\begin{array}{l}\text { Estado del } \\
\text { Paraíba }\end{array}$ & 2015 & 36.778 & 489.898 & 13.32 \\
\cline { 2 - 5 } & 2015 & 850 & 5.974 & 8.96 \\
\hline
\end{tabular}

Fuente: IBGE y EMBRAPA. 
Esta escala de producción creciente, como está descrito en la figura anterior, muestra que ocurrió una mayor producción en el estado, sin embargo su flujo continuó por otros caminos, pudiendo haber sido más absorbido por el mercado interno o haber sido más comercializado por el mercado de otras regiones.

Independientemente de este hecho, la importancia de la barrera es incuestionable, llevando a la afirmación de que el estado de Paraíba gana con la seguridad y con la educación que este puesto de inspección agropecuario de la ciudad de Tacima ha ejercido con el correr de su existencia.

Las enfermedades comunes a los cultivos de maracuyá que deben ser materia de preocupación por parte de la barrera fitosanitaria, son la Antracnosis, Verrugosis, Marchitez por Fusarium, Podredumbre del tallo, Pudrición negra de la fruta, Mancha parda, Mancha bacteriana, Endurecimiento de los Frutos, blanqueamiento de las nervaduras y Virus del mosaico de pepino (VIANA, 2003).

De acuerdo con el agente de inspección de esta barrera, fueron realizadas acciones de orientación y adecuación para los agricultores y personas vinculadas a esta actividad, contribuyendo para que ocurriese un mejor transporte de los elementos trabajados por los mismos.

\section{CONCLUSIONES}

La barrera fitosanitaria agropecuario de la ciudad de tacima se muestra importante para controlar la entrada y salida de productos que podrían ser fuertes transmisores de patógenos, los cuales traerían pérdidas a toda una región y por eso pueden contribuir para la disminución del tránsito de estos vegetales inadecuados.

Esta barrera asciende en importancia, pues derivado de la actividad allí realizada, respaldan y guardan la integridad y las cuestiones económicas directamente envueltas, primando por la educación y por el cumplimiento de la legislación vigente para nuestra región (HILMAN, 2013).

\section{REFERENCIAS}

ADAPEC (Agência de Defesa Agropecuária do Estado de Tocantins). Fiscalização Do Trânsito De Vegetais. 2017. Disponível em: <http://adapec.to.gov.br/fiscalizacao-dotransito-de-vegetais/>. Acesso em: 28 ago. 2017. 
AGED (Agência Estadual de Defesa Agropecuária do Maranhão). Barreiras Zoofitossanitárias. Disponível em: <http://www.aged.ma.gov.br/barreiraszoofitosanitarias/>. Acesso em: 29 ago. 2017.

AGRODEFESA (Agência Goiana de Defesa Agropecuária). Fiscalização Vegetal. 2014. Disponível em: <http://www.agrodefesa.go.gov.br/post/ver/186686/fiscalizacao-vegetal>. Acesso em: 28 ago. 2017.

ARAÚJO, J.L.P.; ARAÚJO, E.P.; CORREIA, R.C. Análise do custo de produção e rentabilidade do maracujá explorado na região do Submédio São Francisco. Petrolina: Embrapa Semiárido, 2005. (Comunicado Técnico 122).

BRASIL. Ministério da Agricultura, Pecuária e Abastecimento. Instrução Normativa $\mathrm{n}^{\circ}$ 54, de 04 de dezembro de 2007. Aprova a Norma Técnica para a utilização da Permissão de Trânsito de Vegetais - PTV. Diário Oficial [da] República Federativa do Brasil, Brasília, DF, 2007.

BRASIL. Ministério da Agricultura, Pecuária e Abastecimento. Instrução Normativa ${ }^{\circ}$ 41, de 01 de julho de 2008. Altera a Lista de Pragas Quarentenárias Presentes e Ausentes. Diário Oficial [da] República Federativa do Brasil, Brasília, DF, 2008.

BUAINAIN, A.M.; VIEIRA, P.A.; CURY, W.J.M. (Org.). Gestão do risco e seguro na agricultura brasileira. Rio de Janeiro: Funenseg, 2011.

CACHATORI, J.R. Desenvolvimento de Metodologia para o diagnóstico de Pseudomonassyringaepv. aptata, agente causal da mancha bacteriana das folhas de beterraba. 72 f. Dissertação (Mestrado em Sanidade, Segurança Alimentar e Ambiental no Agronegócio). Instituto Biológico, Agência Paulista de Tecnologia dos Agronegócios, São Paulo. 2011.

DIAS, V.S.; OLIVEIRA, M.R.V.; PAULA, S.V. Risco de introdução de pragas invasoras exóticas na importação de flores frescas. Brasília: EMBRAPA (Empresa Brasileira de Pesquisa Agropecuária). (Comunidade Técnico, 68). 2002. 
EMBRAPA (Empresa Brasileira de Pesquisa Agropecuária). Dados estatísticos do maracujá. 2016.2 Disponível em: <http://www.cnpmf.embrapa.br/Base_de_Dados/index_pdf/dados/brasil/maracuja/b1_maracu ja.pdf>. Acesso em: 26 jun. 2018.

FERNANDES, L.V.P. A efetividade das barreiras fitossanitárias internas: o caso das barreiras nas Centrais de Abastecimento (CEASAS) de Minas Gerais. 52 f. Dissertação (Mestrado Profissional em Defesa Sanitária Vegetal)-Universidade Federal de Viçosa, Viçosa. 2016.

GIL, A.C. Como elaborar projetos de pesquisa. São Paulo: Atlas, 2002.

HILMAN, R. As barreiras fitossanitárias interestaduais no Brasil: localização e avaliação técnica. 57 f. Dissertação (Mestrado Profissional em Defesa Sanitária Vegetal)-Universidade Federal de Viçosa, Viçosa. 2013.

LIMA, J.D.; LIMA, E.Q.; JESUS, J.V.; LEITE, A.M.R.; BATISTA, F.F.; ARAÚJO, R.C.; ARAÚJO, A.E. Situação da bananicultura no município de Bananeiras e indicadores para atividades de formação dos produtores. In: ENCONTRO DE EXTENSÃO, 11., Resumos... João Pessoa: Universidade Federal da Paraíba, 2009, p. 1.

LIMA, J.C.R. Trânsito e risco fitossanitário da cultura da bananeira no posto de fiscalização agropecuário de Tacima - PB. 22 f. Trabalho de Conclusão de Curso (Graduação em Ciências Agrárias)-Centro de Ciências Humanas, Sociais e Agrárias, Universidade Federal da Paraíba, Bananeiras, 2018.

OLIVEIRA, M.R.V.; NEVILLE, L.E.; VALOIS, A.C.C. Importância ecológica e econômica e estratégias de manejo de espécies invasoras exóticas. Brasília: Embrapa Recursos Genéticos e Biotecnologia. 2001. (Circular Técnica, 8).

PARANÁ (ESTADO). Lei n 11.200, de 13 de novembro de 1995. Dispõe sobre definição e normas para a Defesa Sanitária Vegetal no Estado do Paraná. 1995. Disponível em: <http://www.floresta.ufpr.br/alias/lpf/public_html/legisl34.html>. Acesso em: 29 ago. 2017. 
VIANA, F.M.P.; FREIRE, F.C.O.; CARDOSO, J.E.; VIDAL, J.C. Principais doenças do maracujazeiro na região Nordeste e seu controle. Fortaleza: Embrapa Agroindústria Tropical, 2003. (Comunicado técnico 86).

VIEIRA, M.B. Identificação e Avaliação do Risco de Introdução de Insetos Exóticos no Brasil através da Importação de Bonsai. 33 f. Monografia (Licenciatura em Ciências Biológicas)-Faculdades de Ciências da Saúde, Centro Universitário de Brasília, Brasília. 2002. 